COMUNICAÇÃO CIENTÍFICA

\title{
PODRIDÃO PEDUNCULAR E QUALIDADE DE MANGAS 'TOMMY ATKINS' PROCEDENTES DO MERCADO ATACADISTA DE CAMPINA GRANDE-PB ${ }^{1}$
}

\author{
ERBS CINTRA DE SOUZA GOMES², PERLA JOANA SOUZA GONDIM ${ }^{2}$, \\ MARY DE FÁTIMA GUEDES DOS SANTOS², LUCIANA CORDEIRO DO NASCIMENTO, \\ JACINTO DE LUNA BATISTA ${ }^{3}$, SILVANDA DE MELO SILVA ${ }^{3}$
}

RESUMO - O Brasil destaca-se no cenário mundial como um dos maiores produtores de manga (Mangifera indica L.). No entanto, perdas significativas são observadas em todas as etapas da cadeia produtiva, sobretudo na comercialização varejista, sendo estas correlacionadas em quase sua totalidade à incidência de doenças fúngicas. Neste sentido, objetivou-se com este trabalho determinar a incidência natural de Lasiodiplodia theobromae, agente causal da podridão peduncular, e aspectos da qualidade pós-colheita de mangas 'Tommy Atkins', comercializadas no mercado atacadista da Empresa Paraibana de Abastecimento e Serviços Agrícolas (EMPASA) de Campina Grande-PB. Para a determinação da incidência natural da doença, coletaram-se 40 frutos no estádio de maturação 'de vez', de quatro diferentes estabelecimentos de comercialização, que foram encaminhados ao Laboratório de Fitopatologia (CCA/UFPB). Após sanificação, os frutos foram mantidos sob condições ambientes $\left(28 \pm 2{ }^{\circ} \mathrm{C}\right.$ e UR $\left.75 \pm 6 \%\right)$ por oito dias, determinando-se o aparecimento dos primeiros sintomas e sinais do patógeno. As características de qualidade foram determinadas através da coleta de 10 frutos de cada estabelecimento de comercialização da EMPASA. Os frutos foram transportados ao Laboratório de Biologia e Tecnologia Pós-Colheita (CCA/UFPB), onde foram avaliados quanto aos teores de Sólidos Solúveis (SS), Acidez Titulável (AT), Relação SS/AT e pH. Os dados foram submetidos à análise de variância, e as médias, comparadas pelo teste de Tukey, a 5\% de probabilidade. A manga comercializada no mercado atacadista da EMPASA de Campina Grande apresentou baixo conteúdo de SS e elevada AT, caracterizando fruto no início da maturação. Os frutos apresentaram $88,9 \%$ de incidência natural de podridão peduncular no oitavo dia de armazenamento, o que compromete a qualidade do produto no varejo, constituindo-se em uma causa das elevadas perdas pós-colheita.

Termos para indexação: Mangifera indica, Lasiodiplodia theobromae, qualidade pós-colheita, perdas no varejo.

\section{STEM-END ROT AND QUALITY OF 'TOMMY ATKINS' MANGOS FROM THE WHOLESALE MARKET OF CAMPINA GRANDE-PB, BRAZIL}

\begin{abstract}
Brazil stands out as one of the largest producers of mango (Mangifera indica L.) in the world. However, significant losses are observed in all stages of production chain, mainly in the retail market, which are correlated almost entirety to incidence of fungal diseases. In this way, the objective of this study was to determine the incidence of natural infection of Lasiodiplodia theobromae, causal agent of stem-end rot, and postharvest quality of 'Tommy Atkins' mangos, traded in the wholesale market of the Central de Abastecimento (EMPASA) from Campina Grande, State of Paraíba, Brazil. To determine natural incidence of the disease it was collected 40 fruits at mature-green maturity stage from four different wholesale marketing stores at EMPASA that were sent to the Laboratory of Phytopathology (CCA/UFPB). After sanitization, fruits were kept at room conditions $\left(28 \pm 2{ }^{\circ} \mathrm{C}\right.$ and $\left.\mathrm{RH} 75 \pm 6 \%\right)$ during eight days, determining first symptoms and signals of the pathogen. The characteristics of quality were determined by collecting 10 fruits from each wholesale marketing store. Fruits were transported to the Laboratory of Biology and Postharvest Technology (CCA/UFPB), where it was evaluated Soluble Solids (SS), Titratable Acidity (TA), SS/TA, and $\mathrm{pH}$. Data were subjected to variance analysis and the means compared by the Tukey test at $5 \%$ of probability. Mango commercialized in the wholesale market of EMPASA, Campina Grande, showed low SS and high TA contents characterizing fruit at the beginning of maturation. Fruits showed $88.9 \%$ of natural incidence of stem-end rots in the eighth day of storage, which is deleterious for retail quality of fruits, characterizing a causal factor for the higher postharvest losses.
\end{abstract}

Index terms: Mangifera indica, Lasiodiplodia theobromae, postharvest, retail losses.

\footnotetext{
${ }^{1}$ (Trabalho 233-09). Recebido em: 12-10-2009. Aceito para publicação em: 05-03-2010.

${ }^{2}$ Programa de Pós-Graduação em Agronomia/CCA/UFPB. Campus II, CEP: 58.973.000, Areia -PB, e-mails: ectecnologo@hotmail.com; pgondim@yahoo.com.br; mary_guedes_ap@hotmail.com

${ }_{3}^{3}$ Prof., Programa de Pós-Graduação em Agronomia/CCA/UFPB. Campus II, CEP: 58397-000, Areia - PB, e-mail: luciana.cordeiro@cca.ufpb.br
} 
O Brasil é o maior produtor mundial de frutas tropicais e, devido à diversidade de solo e de clima, é possível a produção de frutas de clima temperado e subtropical, produtos com potencial para o mercado externo (FAO, 2009). Dentre as principais fruteiras tropicais, a mangueira (Mangifera indica L.), uma espécie frutífera, dicotiledônea, da família Anacardiaceae, ocupa lugar de destaque no cenário nacional. Seus principais produtores mundiais são Índia, China, Tailândia, México, Indonésia e Brasil (FAO, 2009). No Brasil, os principais produtores de manga são os Estados da Bahia e São Paulo, com cerca de 55\% da área plantada e $58 \%$ do total produzido (CARDOSO et al., 2007). No Estado do Rio Grande do Norte, o município de Touros é reconhecido produtor regional da manga 'Tommy Atkins (IBGE, 2009), sendo esta a principal origem do fruto comercializado no mercado atacadista do município de Campina Grande-PB, e circunvizinhança (CDLCG, 2007).

Atualmente, o mercado de frutas exige produtos de alta qualidade, o que tem direcionado os produtores a buscarem tecnologias para se adequarem à nova realidade dos consumidores. A ausência de padrões predefinidos para a comercialização de frutos resulta em elevados índices de perdas durante o processo de comercialização varejista (CHITARRA;CHITARRA, 2005). Para Gomes (1996), embora os índices estimados de perdas apresentem dados subjetivos e muitas vezes divergentes, são consensuais quanto à ocorrência de perdas significativas que poderiam ser evitadas, desde que medidas específicas fossem adotadas para identificá-las e reduzi-las.

As doenças pós-colheita podem iniciar no campo e ficar latentes, manifestando-se somente após a colheita em condições ambientais favoráveis (GOMES, 1996) ou, ainda, em condições inadequadas de armazenamento. A redução das perdas pós-colheita na cadeia produtiva de frutos representa um constante desafio, considerando que estes são órgãos que apresentam alto teor de água e nutrientes e, mesmo depois da colheita, mantêm vários processos biológicos, apresentando desta forma maior predisposição a distúrbios fisiológicos, danos mecânicos e ocorrência de podridões (CHITARRA;CHITARRA, 2005).

Dentre os principais problemas fitossanitários que acometem a pós-colheita de frutos de mangueira, as podridões causadas por Lasiodiplodia theobromae (Pat.) Griffon e Maubl têm-se destacado pela alta severidade (OLIVEIRA et al., 2006), existindo registros do patógeno em todas as regiões produtoras do mundo, causando danos quando o pedúnculo da fruta é infectado, devido à podridão peduncular e a infecções nas partes laterais da polpa, que a desqualifica para o mercado (ANGEL et al., 2006), sendo esta uma das principais causas das perdas póscolheita de manga.

Neste sentido, diante da importância que essa fruta representa na cadeia produtiva, objetivou-se com este trabalho determinar a incidência natural de L. theobromae e a qualidade pós-colheita de frutos de mangueira 'Tommy Atkins', comercializados na Empresa Paraibana de Abastecimento e Serviços Agrícolas (EMPASA), Campina Grande, Paraíba.

Amostras de manga 'Tommy Atkins' foram coletadas no estádio de 'vez', com coloração da polpa segundo escala 3 (FREIRE JÚNIOR et al., 1999) e padronização estabelecida por GTZ (1992), no mercado atacadista da Empresa Paraibana de Abastecimento e Serviços Agrícolas (EMPASA), Campina Grande, e levadas ao Laboratório de Fitopatologia do Centro de Ciências Agrárias, da Universidade Federal da Paraíba, para a determinação da incidência natural de $L$. theobromae. O experimento foi desenvolvido em fevereiro de 2008, no período de pico de safra, no município de Touros, Rio Grande do Norte, polo de produção de manga, principal origem do fruto comercializado no atacado no município de Campina Grande-PB (CDLCG, 2007).

Para a determinação da incidência natural da podridão peduncular, foram coletados 40 frutos, aleatoriamente, de quatro estabelecimentos de comercialização atacadista da EMPASA, totalizando 160 frutos. No Laboratório, os frutos foram lavados com água e sabão, postos para secar por $10 \mathrm{~min}$ sendo, posteriormente, mantidos em câmara úmida, envolvidos por sacos de polietileno transparentes, por 24 horas. Em seguida, os frutos permaneceram em condições-ambiente $\left(28 \pm 2{ }^{\circ} \mathrm{C}\right.$ e UR $\left.75 \pm 6 \%\right)$ por oito dias, sendo monitorado diariamente o aparecimento dos primeiros sintomas e sinais do patógeno.

Para a determinação das características de qualidade dos frutos, foram coletados, aleatoriamente, 10 frutos de cada estabelecimento de comercialização atacadista, totalizando 40 frutos em estádio de maturação comercial. Os frutos foram encaminhados ao Laboratório de Biologia e Fisiologia de Pós-Colheita, do Centro de Ciências Agrárias, da Universidade Federal da Paraíba, para avaliação de Sólidos Solúveis (SS - \%), Acidez Titulável (AT- \% de ácido cítrico, Relação SS/AT e pH (INSTITUTO ADOLF LUTZ, 2005).

O delineamento experimental utilizado foi em blocos ao acaso, com quatro repetições, sendo cada repetição constituída por um estabelecimento de comercialização atacadista, de onde foram coletados 40 frutos para a determinação da incidência natural de $L$. theobromae e 10 frutos para a determinação das 
características de qualidade pós-colheita dos frutos. Os dados foram submetidos a análise de variância, e as médias, comparadas pelo teste de Tukey, a 5\% de probabilidade.

As mangas “Tommy Atkins' avaliadas apresentaram elevada incidência média de $L$. theobromae logo no início das avaliações, a qual aumentou progressivamente no decorrer do período pós-colheita (Tabela 1).

Em geral, os primeiros sintomas da doença apareceram três dias após o armazenamento, sendo os maiores índices de incidência observados após oito dias de armazenamento, quando, em média, $88,9 \%$ dos frutos apresentavam sintomas. Observou-se, em mais de $50 \%$ dos frutos infectados, a presença de lesões, tanto no pedúnculo, como nas partes laterais da polpa. Os sintomas mais comumente observados foram necrose dos tecidos, evoluindo para rachadura da epiderme, com exsudação de líquido. Os mesmos sintomas foram descritos por Angel et al. (2006) como característicos da podridão peduncular, cujo agente causal é o fungo $L$. theobromae.

Após a expressão dos sintomas e para a confirmação do agente causal, procedeu-se o isolamento do patógeno através da desinfestação superficial de fragmentos de tecidos lesionados de 10 frutos coletados aleatoriamente, os quais foram plaqueados em meio batata dextrose ágar (BDA). As placas foram incubadas por sete dias, à temperatura de $28 \pm 2{ }^{\circ} \mathrm{C}$, sob alternância luminosa ( $12 \mathrm{~h}$ luz/ $12 \mathrm{~h}$ escuro). Após o período de incubação, procedeu-se a identificação dos fungos, adotando-se os critérios internacionais descritos por Rossman et al. (1994), com base nas observações micromorfológicas das culturas.

Não foram observadas diferenças significativas entre as características de qualidade obtidas de mangas coletadas nos diferentes estabelecimentos de comercialização atacadista (Tabela 2), o que indica homogeneidade na colheita nos locais de cultivo dos frutos, recebidos na Empresa Paraibana de Abastecimento e Serviços Agrícolas - EMPASA, Campina Grande, e comercializados no atacado. Entretanto, o conteúdo médio de sólidos solúveis da manga $(\cong 7 \%)$ é ainda baixo, e a acidez titulável, alta (HOJO et al., 2009), indicando ser o estádio de colheita no início da maturação (GOWDA;HUDDARD, 2001) para o mercado atacadista. Neste estádio os frutos ainda não apresentam os atributos sensoriais desejáveis ao consumo como fruta fresca. Para Hojo et al. (2009), os valores ideais de SS para a comercialização e consumo de mangas "Tommy Atkins" são próximos a 12\%. Lucena et al. (2007), avaliando as alterações físico-químicas de mangas "Tommy Atkins" com idades variando de 95 a 125 dias após a antese, en- contraram valores de SS de 7,5 a 10,9\%.

Os valores referentes à acidez titulável foram superiores aos reportados por Chitarra e Chitarra (2005), 0,65 a $0,70 \%$ de ácido cítrico, sendo essa uma das variáveis utilizadas para a determinação da maturidade fisiológica da manga. No entanto, esses valores assemelham-se aos encontrados por Freire Júnior e Chitarra (1999), avaliando o efeito do cloreto de cálcio nos frutos de manga "Tommy Atkins" tratados hidrotermicamente. Portanto, o baixo teor de sólidos solúveis e a elevada acidez dos frutos resultaram em baixa relação SS/AT, indicando baixa a palatabilidade dos frutos por ocasião da colheita e venda no mercado atacadista. A relação SS/AT é um dos índices mais utilizados para determinar a maturação e a palatabilidade dos frutos, isto por estabelecerem uma relação indicativa do sabor, acentuando-se à medida que a maturação avança e o amadurecimento é atingido (CHITARRA;CHITARRA 2005).

Os valores de $\mathrm{pH}$ de mangas 'Tommy Atkins' neste estudo variaram entre 3,6 a 3,7, estando estes acima dos reportados por Hojo et al. (2009) e Freire Júnior (1999). De acordo com Morais et al. (2002), durante a maturação, as mangas tendem a aumentar o $\mathrm{pH}$ e a diminuir a acidez.

Mangas 'Tommy Atkins' comercializadas no mercado atacadista na EMPASA de Campina Grande, no pico da safra (fevereiro de 2008), apresentaram baixo conteúdo de SS e elevada AT, caracterizando fruto no início da maturação. Estes frutos também apresentavam alta incidência natural de podridão peduncular que atingiu $88,9 \%$ no oitavo dia de armazenamento, reduzindo significativamente a vida útil dos frutos, que comprometem diretamente a qualidade do fruto para consumo como fruta fresca e elevam as perdas pós-colheita. 
TABELA 1 - Incidência (\%) de Lasiodiplodia theobromae em mangas 'Tommy Atkins' oriundas da Empresa Paraibana de Abastecimento e Serviços Agrícolas - EMPASA. Campina Grande-PB. 2008. Média de 40 frutos por estabelecimento atacadista.

\begin{tabular}{ccccccccc}
\hline Estabelecimento & \multicolumn{7}{c}{ Dias de armazenamento } \\
\cline { 2 - 9 } Atacadista & 1 & 2 & 3 & 4 & 5 & 6 & 7 & 8 \\
\hline 1 & - & - & $18,7 \mathrm{~b}$ & $32,0 \mathrm{~b}$ & $49,3 \mathrm{~b}$ & $62,7 \mathrm{~b}$ & $79,3 \mathrm{ab}$ & $90,7 \mathrm{a}$ \\
2 & - & - & $25,4 \mathrm{ab}$ & $49,3 \mathrm{a}$ & $58,7 \mathrm{~b}$ & $79,1 \mathrm{a}$ & $91,1 \mathrm{a}$ & $93,4 \mathrm{a}$ \\
3 & - & - & $24,0 \mathrm{ab}$ & $25,3 \mathrm{~b}$ & $50,7 \mathrm{~b}$ & $66,7 \mathrm{ab}$ & $80,7 \mathrm{ab}$ & $87,5 \mathrm{a}$ \\
4 & - & - & $26,7 \mathrm{a}$ & $29,3 \mathrm{~b}$ & $49,3 \mathrm{~b}$ & $58,2 \mathrm{~b}$ & $70,9 \mathrm{~b}$ & $84 \mathrm{a}$ \\
\hline $\mathrm{CV}$ & - & - & 16,5 & 14,6 & 20 & 11,8 & 12,4 & 11 \\
\hline DMS & - & - & 7,3 & 9,3 & 19,5 & 14,7 & 18,7 & 18,4 \\
\hline Valores Médios & - & - & 23,7 & 34,0 & 52,0 & 66,7 & 80,5 & 88,9 \\
\hline
\end{tabular}

Médias seguidas de mesma letra na coluna não diferem significativamente entre si, pelo teste de Tukey ( $5 \%)$.

TABELA 2 - Características físico-químicas de mangas ‘Tommy Atkins’ comercializadas no mercado atacadista da Empresa Paraibana de Abastecimento e Serviços Agrícolas - EMPASA. Campina Grande-PB. 2008. Média* de 10 frutos por estabelecimento atacadista.

\begin{tabular}{ccccc}
\hline & \multicolumn{4}{c}{ Características físico-químicas ${ }^{* *}$} \\
\cline { 2 - 5 } Estabelecimento Atacadista & SS (\%) & AT (\%) & SS/AT & $\mathrm{pH}$ \\
\hline 1 & $7 \mathrm{a}$ & $0,95 \mathrm{a}$ & $7,5 \mathrm{a}$ & $3,6 \mathrm{a}$ \\
2 & $7 \mathrm{a}$ & $0,77 \mathrm{a}$ & $9,1 \mathrm{a}$ & $3,7 \mathrm{a}$ \\
3 & $7,1 \mathrm{a}$ & $0,76 \mathrm{a}$ & $9,4 \mathrm{a}$ & $3,6 \mathrm{a}$ \\
4 & $6,8 \mathrm{a}$ & $0,83 \mathrm{a}$ & $8,3 \mathrm{a}$ & $3,6 \mathrm{a}$ \\
\hline CV & 6,01 & 11,2 & 13,54 & 3,22 \\
\hline DMS & 0,93 & 0,20 & 2,57 & 0,26 \\
\hline Valores Médios & $6,97 \%$ & $0,83 \%$ & $8,57 \%$ & $3,62 \%$ \\
\hline
\end{tabular}

*Médias seguidas de mesma letra na coluna não diferem significativamente entre si, pelo teste de Tukey (5\%). **AT - Acidez tilulável, expressa em \% de ácido cítrico; SS - Sólidos solúveis, expresso em \%. 


\section{AGRADECIMENTOS}

Ao $\mathrm{CNPq}$, pelo apoio financeiro através da bolsa de estudos de Doutorado concedida ao primeiro e segundo autores. ( $\mathrm{N}^{\circ}$ dos processos: 130805/2008-4 e 143254/2008-1).

\section{REFERÊNCIAS}

ANGEL, N.D.; RAMOS, M.A.; ORTIZ, D.T.; SÃO JOSE, A.R. Enfermidades del mango. In: OLIVEIRA, S.M.A.; TERAO, D.; DANTAS, S.A.F.; TAVARES, S.C.C.H. (Eds.). Patologia pós-colheita: frutas, olerícolas e ornamentais tropicais. Brasília: EMBRAPA Informação Tecnológica, 2006. p.733-774.

CDLCG - Câmara dos Dirigentes Lojistas de Campina Grande. Estrutura do mercado varejista de Campina Grande. 2007. Disponível em: <http:// www.cdlcampina.com.br/>. Acesso em: 05 dez. 2009.

CHITARRA, M.I.F.; CHITARRA, A.B. Pós-colheita de frutas e hortaliças: fisiologia e manuseio. 2.ed. Lavras: UFLA, 2005. 785p.

FAO - Food and Agriculture Organization of the United Nations. Disponível em: $<$ http://faostat.fao. org $>$. Acesso em: 01 jun. 2009.

FREIRE JÚNIOR, M.; CHITARRA, A.B. Efeito da aplicação do cloreto de cálcio nos frutos da manga 'Tommy Atkins' tratados hidrotermicamente. Pesquisa Agropecuária Brasileira, Brasília, v.34, n.5, p.761-769, 1999.

GOMES, M.S.O. Conservação pós-colheita: frutas e hortaliças. Brasília: EMBRAPA-SPI, 1996. 134p.

GOWDA, I.N.D.; HUDDAR, A.G. Studies on ripening changes in mango (Mangifera indica L.) fruits. Journal of Food Science and Technology, London, v. 38 , n. 2, p. 135-137, 2001.
GTZ - DEUTSCHE GESELLSCHAFT FÜR TECHNISCHE ZUSAMMENARBEIT. Manual de exportación: frutas tropicales y hortalizas. Eschborn, 1992.34p.

HOJO, R.H.; SÃO JOSÉ, A.R.; HOJO, E.T.D.; ALVES, J.F.T.; REBOUÇAS, T.N.H.; DIAS, N.O. Qualidade de manga 'Tommy Atkins' pós-colheita com uso de cloreto de cálcio na pré-colheita. Revista Brasileira Fruticultura, Jaboticabal, v.31, n.1, p.62-70, 2009.

IBGE. Sistema IBGE de recuperação automática - SIDRA: levantamento sistemático da produção agrícola. Disponível em: $<$ http://www.sidra.ibge. gov.br>. Acesso em: 12 set. 2009.

INSTITUTO ADOLFO LUTZ. Normas analíticas do Instituto Adolfo Lutz: métodos químicos e físicos para análises de alimentos. 4.ed. Brasília, 2005. $1018 \mathrm{p}$.

LUCENA, E.M.P.; ASSIS, J.S.; ALVES, R.E.; SILVA, V.C.M.; ENÉAS FILHO, J. Alterações físicas e químicas durante o desenvolvimento de mangas 'Tommy Atkins' no Vale do São Francisco. Petrolina-PE. Revista Brasileira de Fruticultura, Jaboticabal, v. 29, n. 1, p. 96-101, 2007.

MORAIS, P.L.D.; FILGUEIRAS, H.A.C.; PINHO, J.L.N.; ALVES, R.E. Ponto de colheita ideal de mangas 'Tommy Atkins' destinadas ao mercado Europeu. Revista Brasileira de Fruticultura, Jaboticabal, v.24, n.3, p.671-675, 2002.

OLIVEIRA, S.M.A.; TERAO, D.; DANTAS, S.A.F.; TAVARES, S.C.C.H. Patologia pós-colheita: frutas, olerícolas e ornamentais tropicais. Brasília: Embrapa Informação Tecnológica, 2006. 855p.

ROSSMAN, A.Y.; PALM, M.E.; SPIELMAN, L.J. A literature guide for the identification of plant pathogenic fungi. St. Paul: APS Press, 1994. 